Article

\title{
Anti-Galling Cold, Dry Forging of Pure Titanium by Plasma-Carburized AISI420J2 Dies
}

\author{
Tatsuhiko Aizawa $^{1, *(\mathbb{D})}$, Tomoaki Yoshino ${ }^{2}$, Yohei Suzuki ${ }^{2}$ and Tomomi Shiratori ${ }^{3}$ \\ 1 Surface Engineering Design Laboratory, Shibaura Institute of Technology, Tokyo 144-0045, Japan \\ 2 Komatsu-Seiki Kosakusho, Co., Ltd., Nagano 392-0022, Japan; yoshino@komatsuseiki.co.jp (T.Y.); \\ y-suzuki@komatsuseiki.co.jp (Y.S.) \\ 3 Faculty of Engineering, University of Toyama, Toyama 930-8555, Japan; shira@eng.u-toyama.ac.jp \\ * Correspondence: taizawa@sic.shibaura-it.ac.jp; Tel.: +81-3-6424-8615
}

check for

updates

Citation: Aizawa, T.; Yoshino, T.;

Suzuki, Y.; Shiratori, T. Anti-Galling Cold, Dry Forging of Pure Titanium by Plasma-Carburized AISI420J2 Dies. Appl. Sci. 2021, 11, 595. https:// doi.org/10.3390/app11020595

Received: 23 November 2020

Accepted: 4 January 2021

Published: 9 January 2021

Publisher's Note: MDPI stays neutral with regard to jurisdictional clai$\mathrm{ms}$ in published maps and institutional affiliations.

Copyright: (C) 2021 by the authors. Licensee MDPI, Basel, Switzerland. This article is an open access article distributed under the terms and conditions of the Creative Commons Attribution (CC BY) license (https:// creativecommons.org/licenses/by/ $4.0 /)$.
Featured Application: Near-net shaping of titanium and titanium alloy workpieces into biomedical parts and devices.

\begin{abstract}
A bare AISI420J2 punch often suffers from severe adhesion of metallic titanium as well as titanium oxide debris particles in dry, cold forging of biomedical titanium alloys. This punch was plasma-carburized at $673 \mathrm{~K}$ for $14.4 \mathrm{ks}$ to harden it up to $1200 \mathrm{HV}$ on average and to achieve carbon supersaturation in the carburized layer. This plasma-carburized punch was employed in the cold, dry forging of a pure titanium wire into a flat plate while reducing the thickness by $70 \%$. The contact interface width approached the forged workpiece width with increasing the reduction ratio. This smaller bulging deformation reveals that the workpiece is upset by homogeneous plastic flow with a lower friction coefficient. This low-friction and anti-galling forging process was sustained by an in situ solid lubrication mechanism. Unbound free carbon was isolated from the carbon-supersaturated AISI420J2 matrix and deposited as a thin tribofilm to protect the contact interface from mass transfer of metallic titanium.
\end{abstract}

Keywords: low-temperature plasma carburizing; high surface hardness; carbon supersaturation; dry, cold forging; high reduction in thickness; free carbon isolation; in situ solid lubrication; intermediate titanium oxide tribofilm formation

\section{Introduction}

Pure titanium and titanium alloys have been highlighted as structural biomedical parts and tools because of their high specific strength and good biocompatibility [1]. Their shaping and forging processes were strictly limited to minimum reduction in thickness due to their risk of galling to stainless steel, WC (Co), and monolithic ceramic dies [2]. Die material selection and design is needed to find a way to enable anti-galling manufacturing to shape and forge raw titanium and titanium alloy workpieces into biomedical parts. The authors proposed a thick $\beta$-SiC-coated $\mathrm{SiC}$ die material for anti-galling forging [3]. As proven by [4], no mass transfer of metallic titanium was seen on the contact interface of a $\beta$ $\mathrm{SiC}$-coated punch to a pure titanium workpiece. The debris particles of $\mathrm{TiO}_{2}$ were prevented from depositing onto this coating surface. This anti-galling process was sustained under in situ solid lubrication by the free carbon isolated from the carbon-supersaturated $\beta$-SiC coating surface and under the in situ formation of intermediate titanium oxide tribofilms on the contact interface. Owing to this galling-free mechanism, a pure titanium wire was forged under cold and dry conditions with a 70\% reduction in thickness [5]. Hence, simple shaping and upsetting can be put into practice in industries by using these $\beta$-SiC-coated $\mathrm{SiC}$ die systems. However, the low toughness of the $\beta$-SiC coating becomes a barrier in further applications of this die material system in the near-net shaping and precise forging of raw titanium and titanium alloys into biomedical parts and tools. 
Plasma carburizing has developed as one of the most reliable surface treatments to harden tool steel and stainless steel dies [6,7]. After [8], a thick carburized layer with a thickness of $30 \mu \mathrm{m}$ was formed at $743 \mathrm{~K}$ for $72 \mathrm{ks}$ onto austenitic stainless steel substrates. Without the precipitation synthesis of chromium and iron carbides, carbon solute content higher than 2 mass\% was attained at the surface of the plasma-carburized layer. This high carbon supersaturation resulted in high hardness, wear toughness, and corrosion resistance. As discussed in [8,9], a fully carbon-supersaturated layer without precipitates was formed by decreasing the holding temperature down to $673 \mathrm{~K}$; however, the carburized layer thickness also decreased down to a few $\mu \mathrm{m}$.

A radio-frequency (RF)-direct current (DC) plasma processing system was developed to build up the experimental setup for low-temperature plasma nitriding and carburizing. The low-temperature nitrogen supersaturation process was performed using this RF-DC plasma processing system [10]. In the case of this RF-DC plasma nitriding with the use of a hollow cathode, a nitrogen-supersaturated layer with a thickness of $60 \mu \mathrm{m}$ formed at $673 \mathrm{~K}$ for $14.4 \mathrm{ks}$. Its average hardness reached $1400 \mathrm{HV}$, and its nitrogen solute content became 4 mass $\%$.

In the present study, this high-density plasma processing system is utilized to supersaturate martensitic stainless steel die substrates with carbon. The case-hardened AISI420J2 is employed as a die material, whereas chromium carbide precipitates are used to strengthen the stainless steel matrix. The carburized AISI420J2 punch is characterized by $X$-ray diffraction (XRD), scanning electron microscopy (SEM), and electron dispersive X-ray spectroscopy (EDX). For the carbides, the homogeneous carbon mapping by EDX as well as the peak shifts of $\alpha^{\prime}$-iron by XRD prove that the AISI420J2 punch is carbon-supersaturated. This punch is fixed into the upper die set for cold, dry forging of pure titanium wires. The power-stroke relationship is monitored in situ to describe this cold, dry forging behavior. The smaller bulging deformation of the forged wires proves that the titanium workpiece is homogeneously upset with low friction. The contact interface between the carburized punch and the titanium workpiece is precisely analyzed by SEM-EDX as well as Raman spectroscopy to describe the free carbon isolation from the carbon-supersaturated matrix of the punch and to investigate the role of isolated carbon as a thin tribofilm for anti-galling forging with low friction.

\section{Experimental Procedure}

A low-temperature plasma carburizing system is stated with comments on the hollow cathode device to intensify the carbon ion density as well as the $\mathrm{CH}$ radical density. A computer numerical control (CNC) stamper is employed for the dry, cold forging experiment while monitoring the power-stroke relationship. The contact interface between the carburized layer and the titanium workpiece is precisely analyzed by SEM-EDX and Raman spectroscopy.

\subsection{Plasma Carburizing System}

An RF-DC plasma processing system (YS-Electric Industry, Co., Ltd., Yamanashi, Japan) was utilized for plasma carburizing. The plasma carburizing setup was placed onto the DC-biased table, as illustrated in Figure 1a. After the diagnosis of the ignited argon plasma in the inside of the hollow [11], the ion and radical densities were increased up to $3 \times 10^{18}$ ions $/ \mathrm{m}^{3}$ in the present setup. Figure $1 \mathrm{~b}$ depicts the ignited plasma under the mixture gas flow. The AISI420J2 punch substrate was covered with a thick plasma sheath in a highly bright condition. In the practical operation, the chamber was evacuated to $0.01 \mathrm{~Pa}$ after placing the punch into the hollow cathode. Under the argon flow, the experimental setup was heated up to the holding temperature of $673 \mathrm{~K}$. The specimen was first presputtered by a DC bias of $500 \mathrm{~V}$ at $70 \mathrm{~Pa}$ under the mixture gas with an argon flow of $160 \mathrm{~mL} / \mathrm{min}$ and a hydrogen flow of $20 \mathrm{~mL} / \mathrm{min}$ for $1.8 \mathrm{ks}$. After presputtering, it was further carburized at $673 \mathrm{~K}$ for $14.4 \mathrm{ks}$ under the mixture of argon, hydrogen, and methane 
$\left(\mathrm{CH}_{4}\right)$. The flow rate of $\mathrm{CH}_{4}$ gas was $20 \mathrm{~mL} / \mathrm{min}$. After carburizing, the system was vented down to $2 \mathrm{kPa}$ in nitrogen and the specimen was cooled in a chamber.

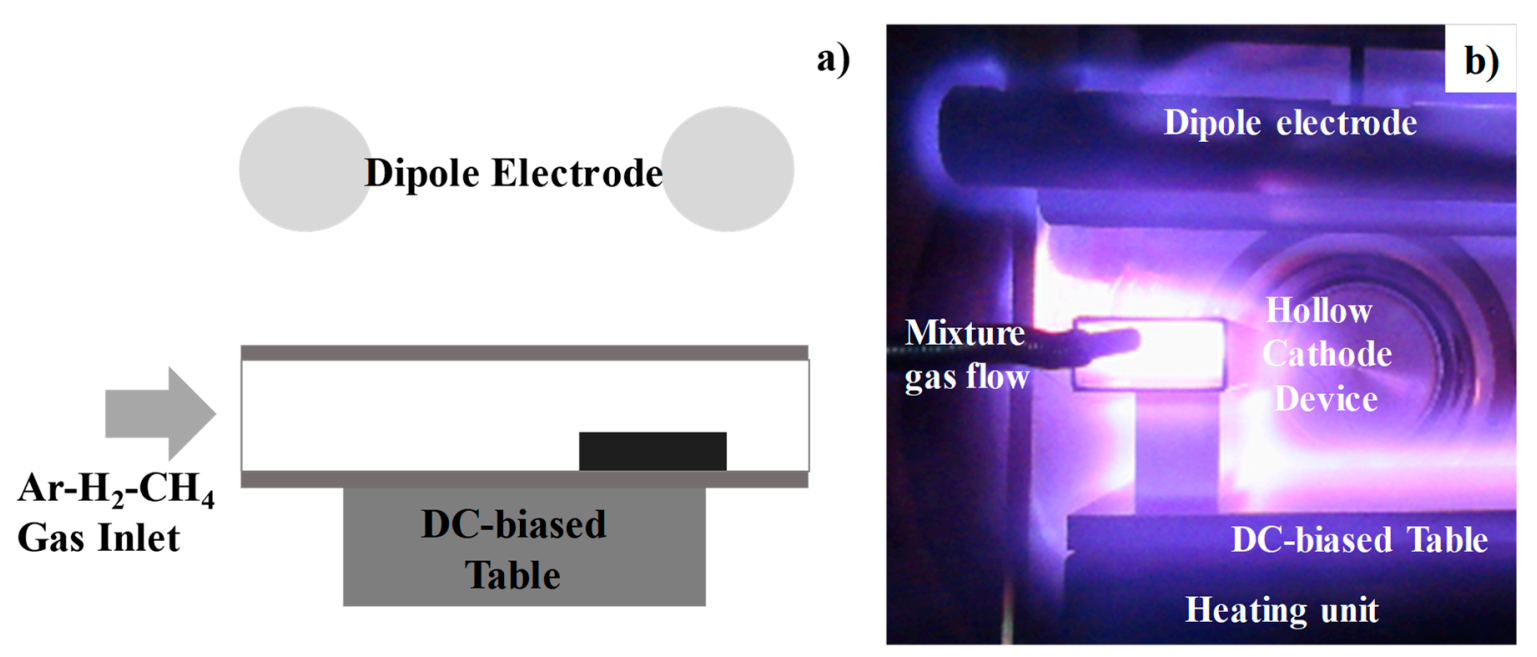

Figure 1. High-density plasma carburizing system with the use of a hollow cathode. (a) Schematic view of the experimental setup, and (b) an image of the plasma carburizing system.

\subsection{CNC Stamping System for Cold, Dry Forging Experiments}

A computer numerical control (CNC) stamper (Hoden Precision, Co., Ltd., Kanagawa, Japan) was utilized to bring the upsetting process down to the specified stroke in reduction, as shown in Figure 2a. In this stamper, four unit motors work independently to compensate for eccentric loading. The torque of each motor was summed up to calculate the applied power and to monitor the power-stroke relationship. The carburized AISI420J2 punch was inserted into the upper cassette die, as depicted in Figure 2b. Both the upper and the lower cassette dies were fixed into each bolster of the CNC stamper. In practical operation, the stroke was lowered at a constant velocity of $0.1 \mathrm{~mm} / \mathrm{s}$ down to the specified minimum stroke $\left(\delta_{\mathrm{m}}\right)$, held for $1 \mathrm{~s}$, and then moved up to the original position at the same velocity. This $\delta_{\mathrm{m}}$ was varied for each reduction in the thickness of the titanium wires.

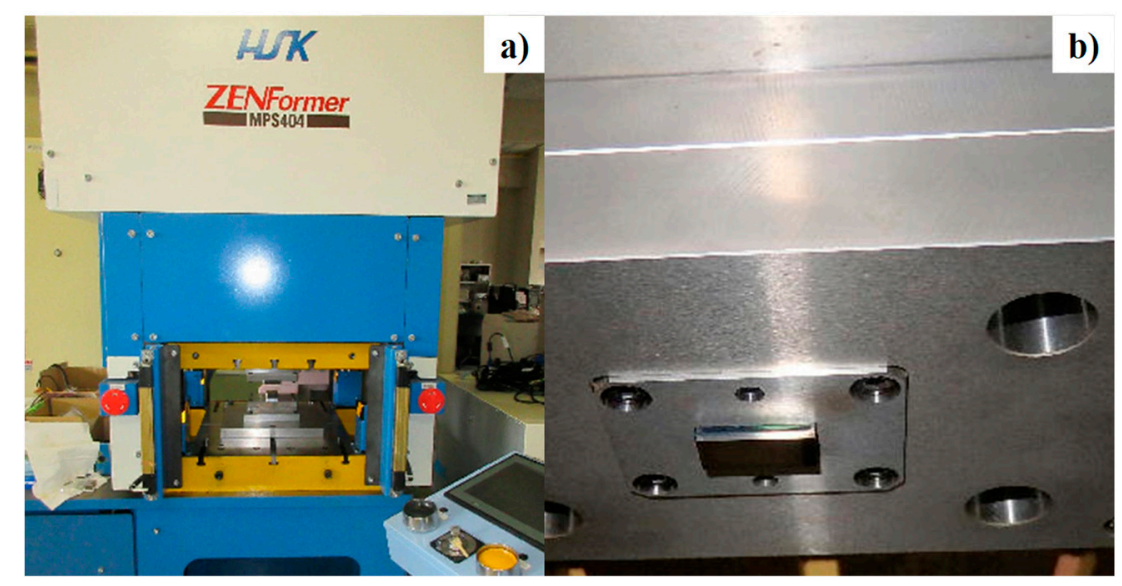

Figure 2. The computer numerical control (CNC) stamping system. (a) The CNC stamper with in situ monitoring of the power-stroke relationship, and (b) the upper cassette die set with the plasma-carburized punch.

\subsection{Contact Interface Analysis}

The contact interface between the carburized AISI420J2 punch and the titanium workpiece was analyzed to describe the in situ lubrication mechanism. Optical microscopy 
(Shimazu, Co., Ltd., Kyoto, Japan) was first employed to understand the morphology of the contact interface on the punch. Several positions were selected to make pointwise SEM-EDX (JOEL, Tokyo, Japan) analyses. In particular, three regions were selected in the contact interface to describe the difference in the in situ solid lubrication. Raman spectroscopy (Nihon-Kogaku, Co., Ltd., Tokyo, Japan) was utilized to analyze the binding state of iron, chromium, titanium, oxygen, and carbon on the interface.

\subsection{Die and Work Materials}

The AISI420J2 substrate was employed as a die with $24 \mathrm{~mm} \times 14 \mathrm{~mm} \times 5 \mathrm{~mm}$ for plasma carburizing. Its chemical composition was as follows: 12.1 mass $\%$ chromium, 0.4 mass $\%$ carbon, 0.5 mass $\%$ silicon, 0.4 mass $\%$ manganese, 0.3 mass $\%$ nickel, 0.2 mass $\%$ potassium and sulfur, and the balance, iron. Its primary temperature was $1223 \mathrm{~K}\left(950{ }^{\circ} \mathrm{C}\right)$, and its tempering temperature was $973 \mathrm{~K}\left(700{ }^{\circ} \mathrm{C}\right)$. Pure titanium with the industrial grade of $\mathrm{T} 328 \mathrm{H}$ was employed as a work material for the forging experiment. Its chemical composition consisted of 0.001 mass $\%$ hydrogen, 0.1 mass $\%$ oxygen, 0.007 mass $\%$ nitrogen, 0.04 mass $\%$ iron, 0.007 mass $\%$ carbon, and titanium in balance.

\section{Experimental Results}

The plasma-carburized AISI420J2 punch was characterized by XRD and SEM-EDX to analyze the carbon-supersaturated iron-chromium matrix and its morphology. The cold, dry forging experiment was performed with the use of this punch to reduce thickness by $70 \%$. The variation in the forged titanium wire shape with increasing this reduction ratio was measured, together with in situ monitoring of the power-stroke relationship. Contact interface analyses were made to describe the in situ solid lubrication mechanism by SEM-EDX and Raman spectroscopy.

\subsection{Plasma Carburizing of AISI420J2 Dies}

$\mathrm{XRD}$ analysis was employed to describe the carbon supersaturation into the martensitic stainless steel matrix at $673 \mathrm{~K}$. After the first-principle calculation of this carbon supersaturation [12], the $\mathrm{Fe}-\mathrm{Cr}$ lattice expands itself by the carbon solute atom occupation of its octahedral vacancy site. Similar to nitrogen supersaturation $[13,14]$, this lattice expansion is detected by the peak shift of the original $\alpha^{\prime}$-lattice to the lower $2 \theta$ direction. Figure 3 depicts the narrow-scanned XRD diagram in the range of $43^{\circ}<2 \theta<46^{\circ}$. The original peak of $\alpha^{\prime}(110)$ at $2 \theta=44.5^{\circ}$ shifts to two peaks at $2 \theta=43.6^{\circ}$ and $43.7^{\circ}$, respectively. As reported for the nitrogen supersaturation of AISI420J2 specimens at $673 \mathrm{~K}$, these peaks correspond to the formation of carbon-supersaturated austenitic and martensitic phases $\left(\gamma_{C}\right.$ and $\left.\alpha_{C}^{\prime}\right)$ of AISI420J2, respectively. The SEM-EDX image of the cross section of the carburized punch reveals that the carburized layer thickness at $673 \mathrm{~K}$ for 14.4 ks reaches $50 \mu \mathrm{m}$.

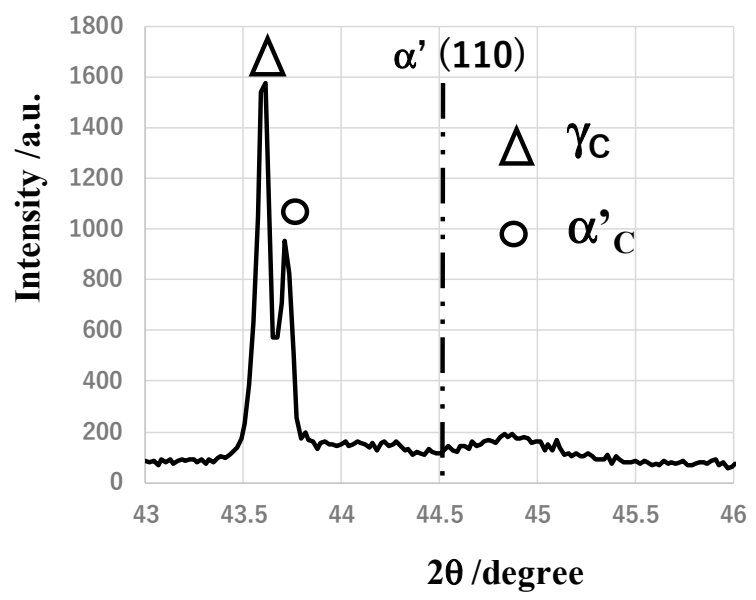

Figure 3. XRD diagram of the surface of the plasma-carburized AISI420J2 punch. 
Figure 4 depicts the SEM-EDX image of the surface of the plasma-carburized AISI420J2 punch with its element mapping. The case-hardened AISI420J2 punch substrate consists of an iron-chromium binary alloy matrix and chromium carbides. For these precipitates, little carbon agglomerate was detected on the binary alloy punch surface. That is, no free or unbound carbon dots were present on the carburized iron-chromium binary alloy matrix surface.
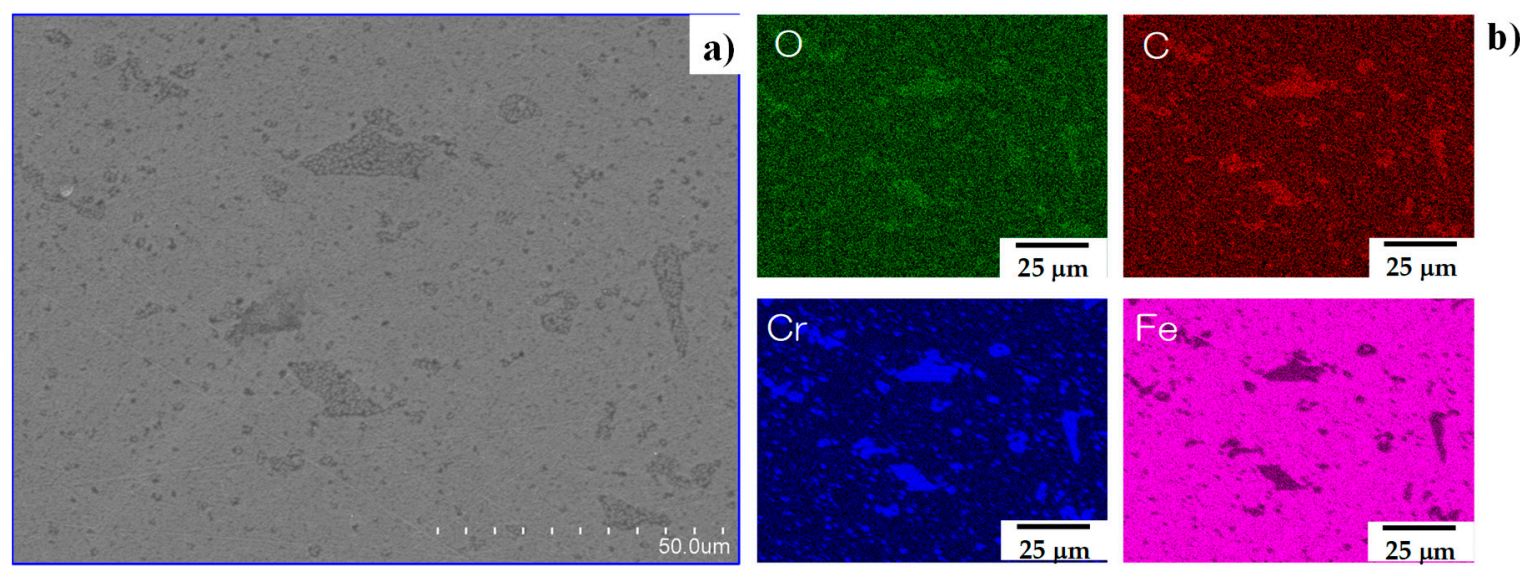

b)

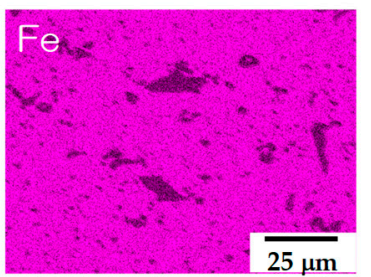

Figure 4. SEM-EDX analysis of the plasma-carburized AISI420J2 punch at $673 \mathrm{~K}$ for $14.4 \mathrm{ks}$. (a) SEM image of the plasma-carburized AISI420J2 punch surface, and (b) its element mapping.

\subsection{Upsetting of Titanium Wire into Thin Flat Plate}

A titanium wire with a diameter of $1.0 \mathrm{~mm}$ and length of $10 \mathrm{~mm}$ was employed as a workpiece for cold, dry forging. The stroke $\left(\delta_{\mathrm{m}}\right)$ was first controlled to move down from the initial position, where the workpiece contacted the punch surface. Then, it was further moved down stepwise to the specified depth; i.e., $\delta_{\mathrm{m}}=0.1 \mathrm{~mm}$ for $r=10 \%$ and $\delta_{\mathrm{m}}=0.7 \mathrm{~mm}$ for $r=70 \%$. Figure 5 a depicts the variation in the cross section for the forged titanium wire with increasing reduction ratio $(r)$. A circular wire was shaped into a flat plate with a thickness of $0.3 \mathrm{~mm}$ at $r=70 \%$ without significant bulging deformation.

Up to $r=30 \%$, the wire was compressed in the axial direction. When $r>30 \%$, its plastic flow became homogeneous in the lateral direction. As shown in Figure 5b, the width of the forged wire (Wo) was larger than the width of the contact interface $(W c)$ for $r<20 \%$. $W_{c}$ approaches Wo with increasing $r$. This proves that the titanium workpiece flows in the lateral direction with homogeneous plastic flow velocity along the contact interface. The surface extension rate reached $170 \%$ of the original wire surface.

Figure 6 shows the variation in these $W_{0}$ and $W_{c}$ as well as the bulging width $(\mathrm{Bg}=(\mathrm{Wo}-\mathrm{Wc}) / 2)$ with increasing $r$. A monotonous increase in Wo and Wc with $r$ implies that a circular wire widens uniformly with upsetting. In particular, a linear increase in Wc with $r$ reveals that the reduced volume of the wire by compression is compensated by its widening volume in the lateral direction. As shown in the monotonic approach of Bg to zero with increasing $r$, the bulging deformation of the wire diminishes with $r$. After [15], this nearly zero bulging deformation for $r>30 \%$ proves that the friction coefficient approaches less than 0.1 . 

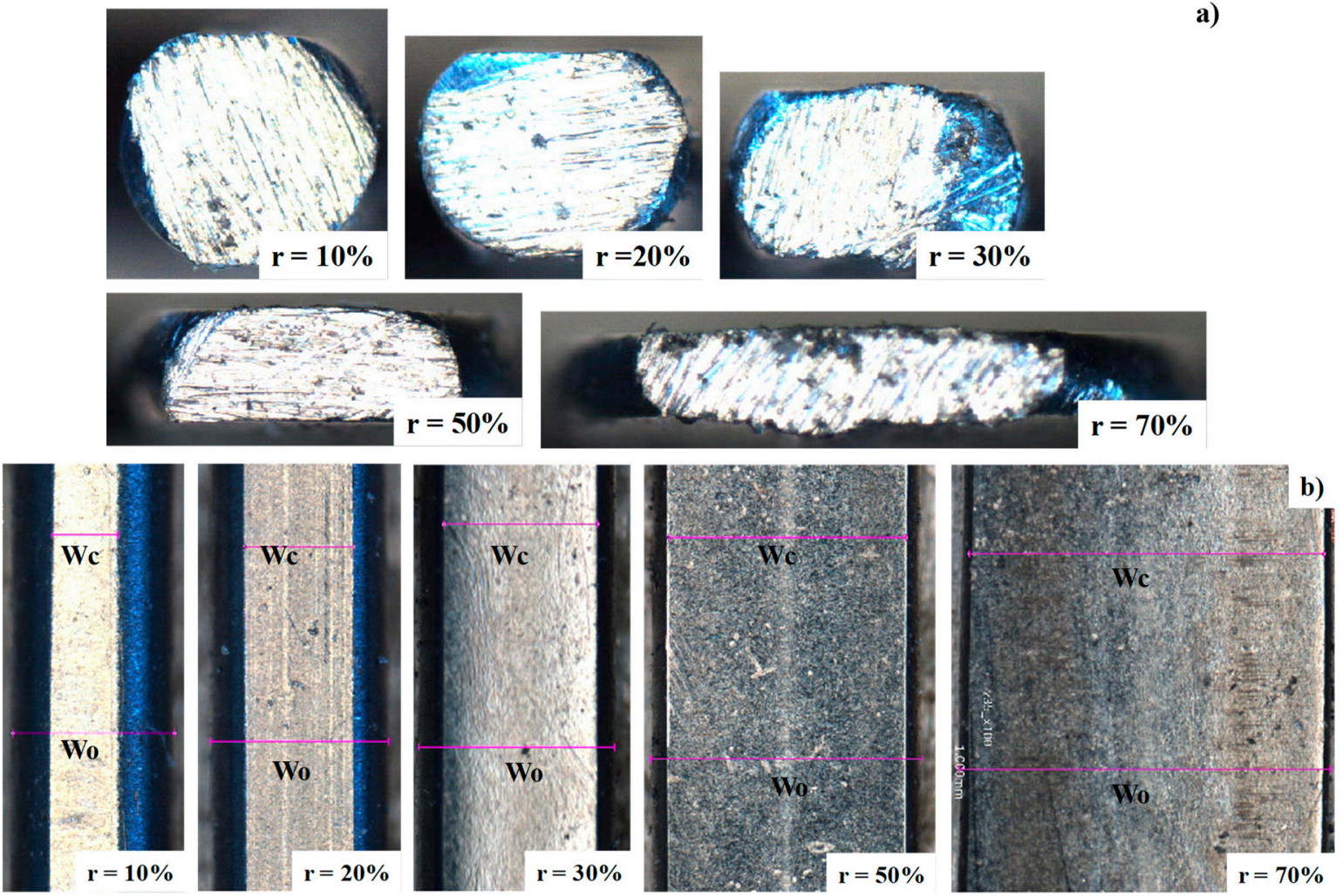

Figure 5. Variation in the cross section and plane views of cold dry forged pure titanium wire with increasing reduction in thickness $(r)$. (a) Variation in the titanium workpiece cross sections with increasing $r$, and (b) variation in the plane view of the forged wire with increasing $r$.

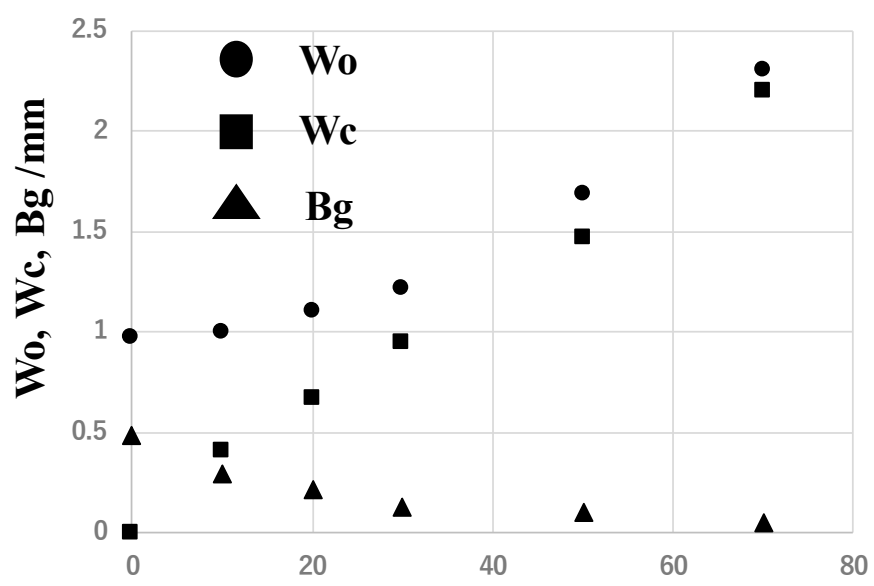

Reduction of thickness, r/\%

Figure 6. Surface area extension with increasing reduction rate, $r$.

Figure 7 depicts the relationship between the applied power $(P)$ and the stroke $(\delta)$ up to the specified reduction rate for $r=10 \%, 20 \%, 30 \%, 50 \%$, and $70 \%$, respectively. The measured $P-\delta$ diagrams for each $r$ superpose on a single master curve; the power increases significantly for $r>30 \%$ due to the work hardening of pure titanium. 


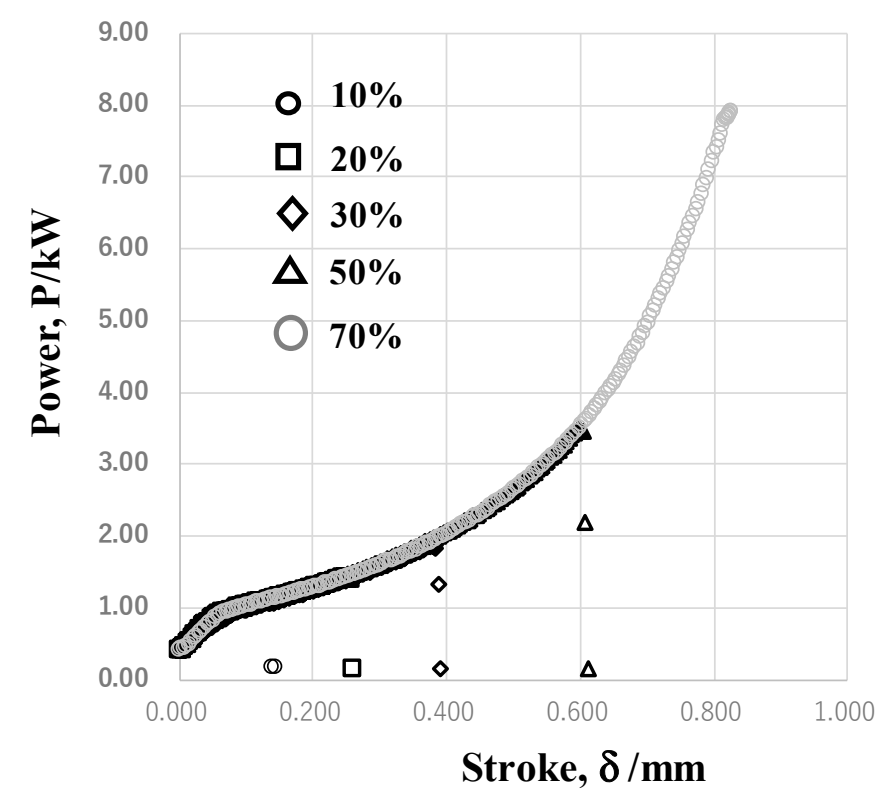

Figure 7. Relationship of the applied power to the stroke for each reduction in thickness.

\subsection{Contact Interface Analysis}

The cold, dry forging experiments up to $r=70 \%$ were continuously performed 10 times to leave a distinct contact interface onto the carburized AISI420J2 punch surface.

Figure 8 depicts a microscopic image of the contact interface of the carburized AISI420J2 and the forged titanium workpiece. Many stripes were formed on this interface radially, from its centerline to its ends, together with the lateral plastic flow of the work material. Three positions were selected for SEM-EDX analyses between the centerline of the interface and its end. Region A was located near the end of the interface, region B was in its middle, and region $C$ was near the centerline.

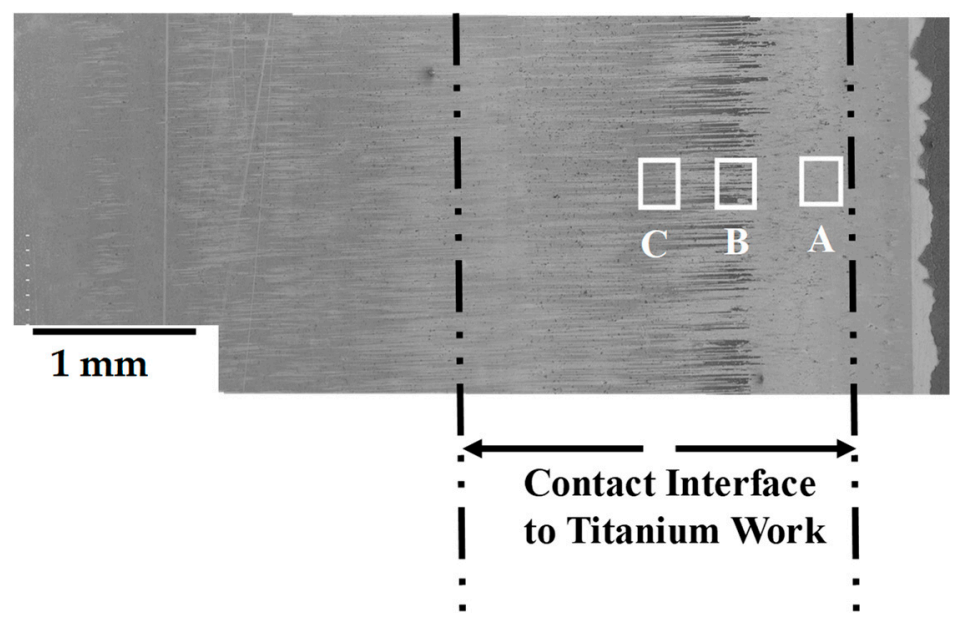

Figure 8. Optical microscopic observation of the contact interface of the carburized AISI420J2 surface and the forged titanium workpiece.

Figure 9 depicts the SEM images of region A and the element mapping of oxygen, carbon, titanium, chromium, and iron, respectively. For the original precipitate of $(\mathrm{Cr}$ and $\mathrm{Fe}$ ) oxides and carbides, the chromium and iron uniformly distribute on the contact interface. Carbon, titanium, and oxygen distribute in stripes radially along the plastic flow direction of the titanium workpiece. Since little carbon is detected, even in trace levels, on the carburized AISI420J2 surface before forging, these carbon stripes come from the carbon solutes isolated from the AISI420J2 matrix. Both the titanium and oxygen stripes are 
exclusively present at the positions without carbon content. This implies that the carbon stripes protect the punch surface from adhesion of titanium.
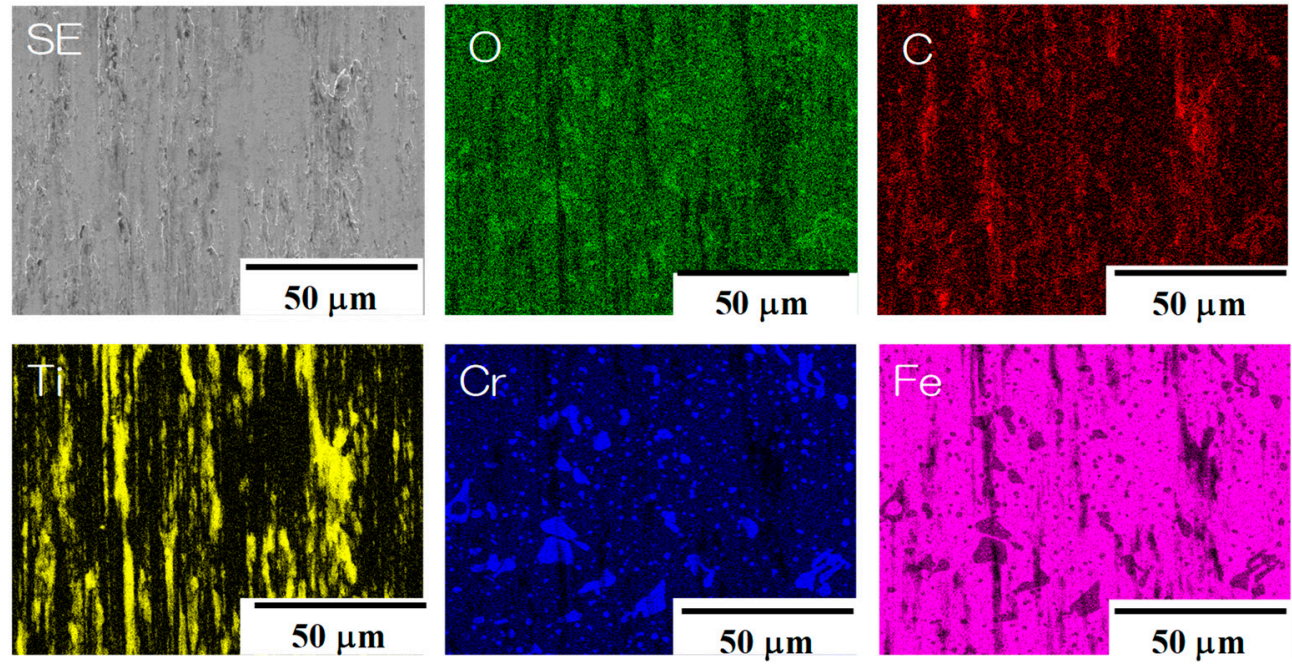

Figure 9. SEM-EDX image and element mapping of region A in the contact interface of the carburized AISI420J2 punch and the titanium workpiece.

Figure 10 also depicts the SEM image of region B with the element mapping in the middle of the contact interface. No change in the chromium and iron maps was detected between regions $\mathrm{A}$ and $\mathrm{B}$. The carbon stripes broaden, while the titanium and oxygen stripes become thinner compared with those in Figure 9. The exclusive presence of carbon stripes on titanium and oxygen ones becomes more distinct than those seen in Figure 9.
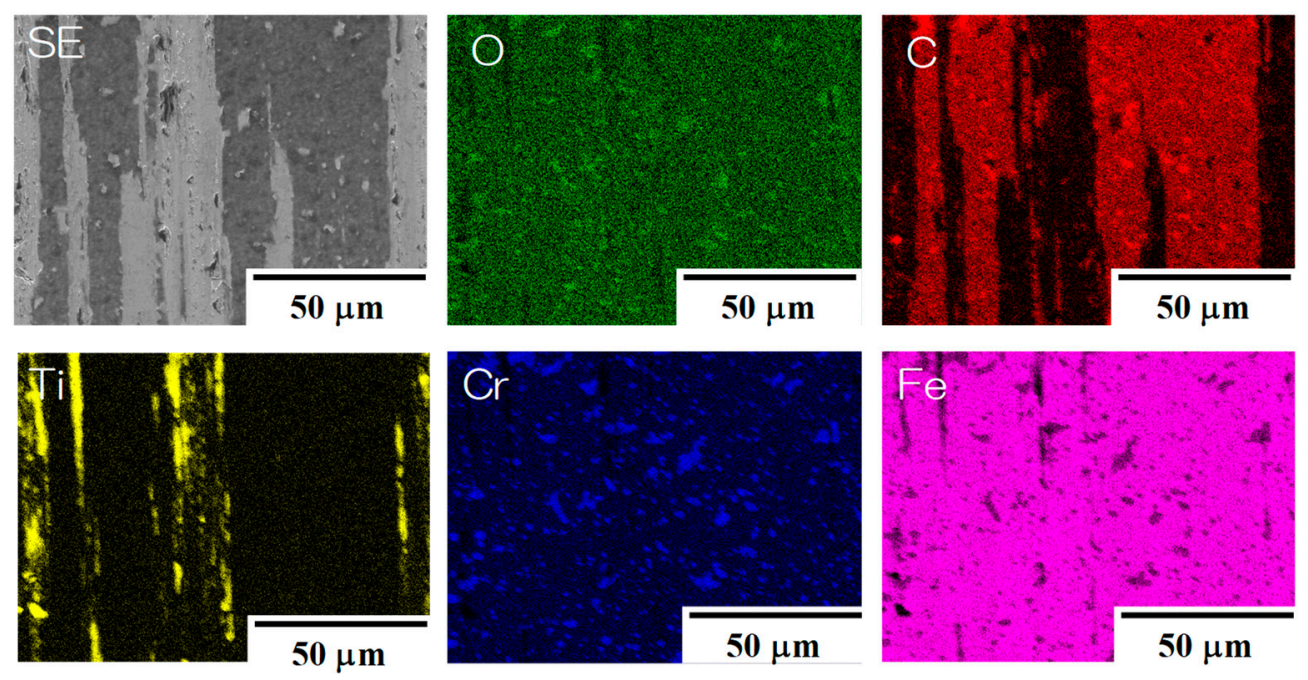

Figure 10. SEM-EDX image and element mapping of region B in the contact interface of the carburized AISI420J2 punch and the titanium workpiece.

Figure 11 shows the SEM and element mapping of region C. A few titanium and oxygen stripes are seen at the centerline of the contact interface. Most of region $C$ is covered with unbound carbon films. Iron and chromium maps are the same as those seen in Figure 4; the punch surface at the center in contact is free from adhesion of titanium. This proves that the punch surface at the initial contact with the titanium workpiece with high static pressure during dry forging is free from galling because of in situ carbon lubrication. Figures 9-11 reveal that the interface area overlapped by the carbon films gradually decreases from the 
centerline of the interface to its end. This suggests that formation of free carbon stripes and films on the interface is driven by the applied stress during dry forging.
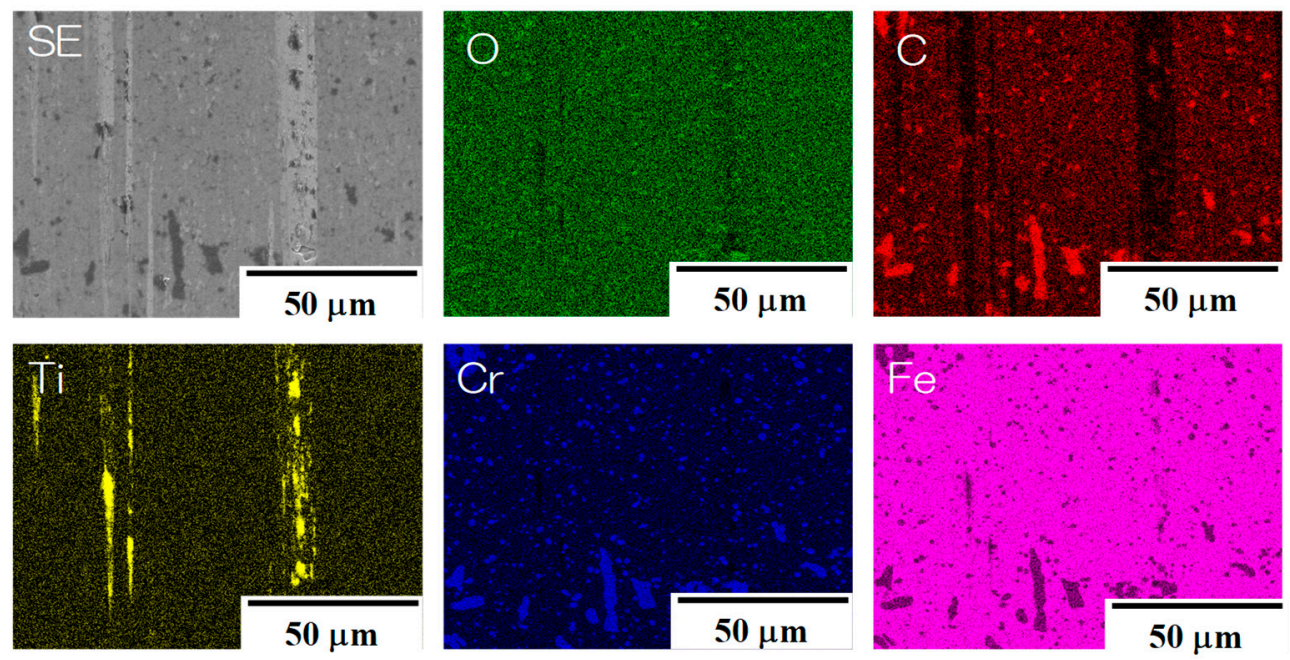

Figure 11. SEM-EDX image and element mapping of region C on the contact interface of the carburized AISI420J2 punch and the titanium workpiece.

\subsection{Raman Spectroscopy}

The binding state of the tribofilm on the contact interface was analyzed by Raman spectroscopy. Figure 12a shows the Raman spectrum at the center of region B. Three broad peaks around $\Lambda=220 \mathrm{~cm}^{-1}, 400 \mathrm{~cm}^{-1}$, and $600 \mathrm{~cm}^{-1}$ are identified by $\mathrm{TiO}_{\mathrm{x}}$, or intermediate titanium oxides, including $\mathrm{TiO}_{2}$, after [16]. This proves that the titanium and oxygen stripes coincident with each other consist of $\mathrm{TiO}_{\mathrm{x}}$ and $\mathrm{TiO}_{2}$.

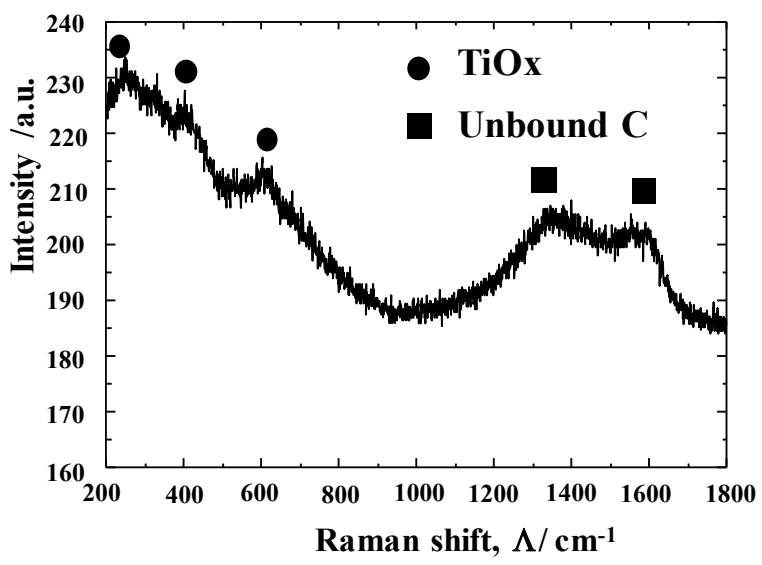

(a)

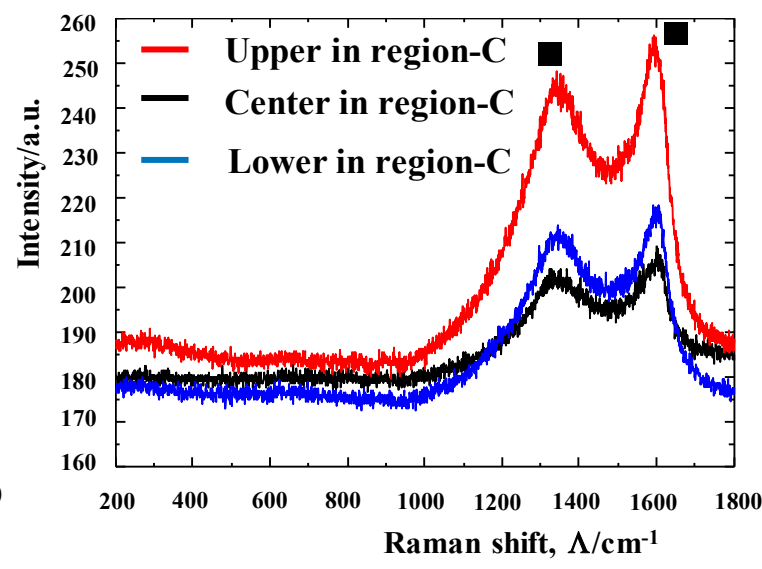

(b)

Figure 12. Raman spectroscopic analyses of the titanium-rich and the carbon-rich zones in the contact interface. (a) Raman spectra of region B, and (b) Raman spectra of region C (three positions are selected for measurement).

If $\mathrm{TiO}_{2}$ were only present as titanium oxide, the narrow peaks would be detected at $\Lambda=400 \mathrm{~cm}^{-1}$ and $600 \mathrm{~cm}^{-1}$. A broader peak around $200 \mathrm{~cm}^{-1}$ suggests that intermediate titanium oxides are formed together with $\mathrm{TiO}_{2}$ debris particles in the titanium and oxygen stripes in Figure 10. As analyzed in the literature [17,18], two broad D- and G-peaks at $\Lambda=1320 \mathrm{~cm}^{-1}$ and $1600 \mathrm{~cm}^{-1}$ in Figure 12a prove that the carbon detected in Figure 10 is unbound from titanium, chromium, and iron. The free carbon stripes in Figure 10 are formed by the carbon isolation from the carburized AISI420J2 matrix of the punch. 
Figure $12 \mathrm{~b}$ depicts the Raman spectra of region $\mathrm{C}$ at the center of the contact interface. Three positions were selected for analysis in this region. In these three spectra, only two broad peaks are detected at $\Lambda=1320 \mathrm{~cm}^{-1}$ and $1600 \mathrm{~cm}^{-1}$, respectively. In correspondence to Figure 11, most of the punch surface at the center of the interface is covered with the free carbon film isolated from the carburized punch matrix.

\section{Discussion}

The formation of a relatively thick carburized layer at $673 \mathrm{~K}$ for $14.4 \mathrm{ks}$ is due to the carbon solute diffusion process and carbon supersaturation. After [10,12-14], the carbon and nitrogen supersaturation processes are common to plasma carburizing and nitriding treatments at $673 \mathrm{~K}$. This supersaturation and diffusion of carbon and nitrogen solutes into stainless steel is recognized by the iron lattice expansion and high solute content depth profile in the carburized and nitrided layers. In addition, the grain refinement takes place with this carbon supersaturation process to sustain the carbon solute diffusion through the fine zone and grain boundaries in a manner similar to the nitrogen supersaturation in $[10,14]$.

A solid material with a two-dimensional structure has been identified as a typical solid lubricant; e.g., $\mathrm{MoS}_{2}$ particles and coatings [19] and graphite [20] are frequently employed in industries to reduce the friction and galling in hot forming. In particular, a graphite mold provides a solution for the mold stamping of oxide glasses to optical lenses [21]; the lens surfaces are often contaminated by the dust of graphite. By contrast, DLC-coated dies often suffer from the adhesion of those glasses as well as metallic titanium, as reported in [22]. As analyzed in Figures 8-12, the unbound, free carbon film formed in situ during cold forging works as a solid lubricant to protect the die surface from the galling of titanium. Since this solid lubrication film is mainly formed only at the high-pressure contact interface, there is little possibility of its contaminating other work surfaces not only in cold forging but also in warm and hot forging.

Isolation of unbound, free carbon solutes from the highly stressed AISI420J2 matrix plays an essential role in the formation of the carbon tribofilm for in situ solid lubrication. Many studies have reported the ordering of carbon atoms in iron and steel under the supersaturated state only in the presence of inner strains [23]. As suggested in [24], the externally applied compressive stress has an influence on carbon-carbon and carbon-iron interactions and induces the separation of supersaturating carbon solutes to ordered carbon and free carbon in stressed steel. This free carbon solute diffuses to the surface by a steep stress gradient and in situ forms a thin film on the contact interface during forging.

An intermediate titanium oxide $\left(\mathrm{TiO}_{\mathrm{x}}\right)$ film is also formed in situ together with the in situ solid lubrication by the carbon film. A few $\mathrm{TiO}_{\mathrm{x}}$ stripes were formed at the center of the contact interface under high compressive stress during forging. With increasing reduction in thickness, the applied stress gradually lowers and the carbon isolation process weakens, so that the $\mathrm{TiO}_{x}$ film is formed on the contact interface away from its center line.

The plasma carburizing conditions have an influence on this carbon supersaturation into the AISI420J2 matrix. In previous studies on low-temperature DC plasma carburizing $[9,10]$, no iron and chromium carbides were synthesized as a precipitate into stainless steel matrices. However, no statements were found in those papers on the plasma diagnosis of the activated species in plasmas. As suggested in [11], the ratio of $\mathrm{CH}_{4}$ to $\mathrm{H}_{2}$ in the mixture gas of argon, $\mathrm{CH}_{4}$, and $\mathrm{H}_{2}$ has an influence on the $\mathrm{CH}$ radical density as well as the ion density of $\mathrm{C}^{*}\left\{\mathrm{C}^{+}, \mathrm{C}^{2+}, \mathrm{C}^{3+}\right.$, and $\left.\mathrm{C}^{4+}\right\}$ in the ignited plasmas for low-temperature plasma carburizing. Further study is needed to optimize this ratio for high densification of $\mathrm{CH}$ radicals to drive the plasma carburizing process.

The plasma-carburized AISI420J2 at $673 \mathrm{~K}$ has anti-galling capacity in forging titanium and titanium alloys, enough to be applied to the net shaping of raw titanium workpieces into biomedical parts. Different from $\beta$-SiC-coated dies [8,9], this die has sufficient toughness and hardness against local stress concentration as well as eccentric loading during 
complex shaping. As noted in [25], this die material selection enables the realization of highly precise shaping with dimensional accuracy from titanium wires and bars.

\section{Conclusions}

The plasma-carburized martensitic stainless steel AISI420J2 provides an alternative die selection to put the anti-galling dry, cold forging of titanium and titanium alloy workpieces into practice. The unbound, free carbon solute isolates from this carbon-supersaturated AISI420J2 matrix and deposits on the highly stressed contact interface. This in situ formed free carbon agglomerate works as a solid lubricant to protect the die surface from the mass transfer of metallic titanium and to reduce friction and wear. Owing to this in situ solid lubrication, the titanium wire with a diameter of $1.0 \mathrm{~mm}$ is upset and shaped into a thin plate with a thickness of $0.3 \mathrm{~mm}$. The nearly zero bulging deformation at a high reduction ratio of thickness proves that a titanium workpiece makes plastic flow homogeneously along the contact interface with a low friction coefficient of 0.1 or less.

The plasma-carburized AISI420J2 die has a high hardness of $1200 \mathrm{HV}$ at the surface and preserves its original ductility and toughness, making it suitable to be used for nearnet forging and shaping with local stress transients and eccentric loading in practical production lines. This mechanical property with anti-galling capacity is preferable to the precise metal forming of titanium wires and bars into biomedical parts.

Author Contributions: Conceptualization, T.A. and T.S.; methodology, T.A. and T.Y.; validation, T.A., T.Y., and Y.S.; investigation, T.A., T.Y., Y.S., and T.S.; data curation, Y.S.; writing-original draft preparation, T.A.; writing-review and editing, T.Y., Y.S., and T.S.; project administration, Y.S. All authors have read and agreed to the published version of the manuscript.

Funding: This research received no external funding.

Acknowledgments: The authors would like to express their gratitude to S. Kurozumi (Nano-Film Cota, LLC) and S. Ishiguro (Graduate School of Engineering, University of Toyama) for their help in the experiments.

Conflicts of Interest: The authors declare no conflict of interest.

\section{References}

1. Kihara, T. Visualization of deforming process of titanium and titanium alloy using high speed camera. In Proceedings of the 2019 JSTP Conference, Kyoto, Japan, 8 June 2019; pp. 41-42.

2. Kataoka, S.; Murakawa, M.; Aizawa, T.; Ike, H. Tribology of dry deep-drawing of various metal sheets wit use of ceramic tools. Surf. Coat. Technol. 2004, 178, 582-590. [CrossRef]

3. Aizawa, T.; Ito, K.-I.; Fukuda, T. SiC-coated SiC die for galling-free forging of pure titanium. Mater. Trans. 2020, 61, 282-288. [CrossRef]

4. Aizawa, T.; Yoshino, T.; Ito, K.-I.; Fukuda, T. Thick $\beta$-SiC CVD-coated SiC die system for dry forging of metals. J. Cryst. 2020, 10, 539. [CrossRef]

5. Aizawa, T.; Yoshino, T.; Fukuda, T.; Shiratori, T. Dry cold forging of pure titanium wire to thin plate with use of $\beta$-SiC coating dies. J. Mater. 2020, 12, 3780.

6. Yoneda, Y.; Takami, S.; Scheuermann, W. Plasma carburizing-A method for industrial application. Haertrei-Tech. Mitt. 1985, 40, 80-84.

7. Edenhofer, B.; Graefen, W.; Mueller-Ziller, J. Plasma-carburizing-A surface heat treatment process for the new century. Surf. Coat. Technol. 2001, 142, 225-234. [CrossRef]

8. Sun, Y. Kinetics of low temperature plasma carburizing of austenitic stainless steels. J. Mater. Proc. Technol. 2005, 168, 189-194. [CrossRef]

9. Egawa, M.; Ueda, N. Low temperature plasma nitriding and carburizing for austenitic stainless steel. Res. Rep. Osaka Prefect. Ind. Res. Inst. 2011, 25, 29-37.

10. Aizawa, T. Low temperature plasma nitriding of austenitic stainless steels. In Stainless Steels and Alloys; IntechOpen: London, UK, 2019; Chapter 3, Volume 3, pp. 31-50.

11. Suenaga, R.; Yunata, E.E.; Aizawa, T. Quantitative plasma diagnosis of high density RF-DC plasmas for surface processing. In Proceedings of the 7th SEATUC Conference, Bandon, Indonesia, 7 March 2013; pp. 63-68.

12. Domain, C.; Becquart, C.S.; Foct, J. Ab initio study of foreign interstitial atom $(\mathrm{C}, \mathrm{N})$ interactions with intrinsic point defects in $\alpha$-Fe. Phys. Rev. B 2004, 69, v144122. [CrossRef] 
13. Kim, S.K.; Yoo, J.S.; Priest, J.M.; Fewell, M.P. Characteristics of martensitic stainless steel nitrided in a low-pressure RF plasma. Surf. Coat. Tech. 2003, 163, 380-385. [CrossRef]

14. Farghali, A.; Aizawa, T. Nitrogen supersaturation process in the AISI420 martensitic stainless steels by low temperature plasma nitriding. ISIJ Int. 2018, 58, 401-407. [CrossRef]

15. Hong, J.J.; Yeh, W.C. Application of response surface methodology to establish friction model of upset forging. Adv. Mech. Eng. 2018, 10, 1-9. [CrossRef]

16. Mohapatra, S.; Mishra, D.; Mishra, G.; Roy, G.; Behera, D.; Mantry, S.; Singh, S. A study on sintered TiO $\mathrm{T}_{2}$ and TiO $2 / \mathrm{SiC}_{\mathrm{C}}$ composites synthesized through chemical reaction based solution method. J. Compos. Mater. 2013, 47, 3081-3089. [CrossRef]

17. Fujisawa, K. Raman spectrum comparison of various carbon materials. Res. Rep. Nagano Technol. Res. Cent. 2014,9 , M33-M35.

18. Osada, M.; Kakihana, M. Application of Raman spectroscopy to characterization of carbon-based materials: Recent advances and their applications to nano-carbon. TANSO 2007, 228, 174-184. [CrossRef]

19. Akbarzadeh, M.; Zandrahimi, M.; Moradpur-Tari, E. Molybdenum disulfide coating on AISI316 stainless steel by thermosdiffusion method. Arch. Met. Mater. 2017, 62, 1741-1748. [CrossRef]

20. Available online: https:/ /itstillruns.com/graphite-lubricant-6385272.html (accessed on 7 December 2020).

21. Kim, K.-H.; Hwang, K.-J.; Lee, H.; Jeong, S.-M.; Lee, M.-H.; Bae, S.-Y. Improvement of adhesion properties of glass prepared using SiC-deposited graphite old via low-temperature chemical vapor deposition. J. Kore Cera. Soc. 2020, 57, 112-118. [CrossRef]

22. Aizawa, T.; Dohda, K.; Shiratori, T. Nano-structured tribo-coating for cold and hot stamping. In Proceedings of the 52nd ICFG Plenay Meeting, San Sebastian, Spain, 16 September 2019; pp. 116-123.

23. Sinclair, C.W.; Perez, M.; Veiga RG, A.; Weck, A. Molecular dynamics study of the ordering of carbon in highly supersaturated $\alpha$-Fe. Phys. Rev. B 2010, 81, 224204. [CrossRef]

24. Maugis, P. A temperature-stress phase diagram of carbon-supersaturated bcc-iron, exhibiting beyond-Zener ordering. J. Phase Equilibria Diffus. 2020, in press. [CrossRef]

25. Elias, C.N.; Lima, J.H.C.; Valiev, B.R.; Meyers, M.A. Biomedical applications of titanium and titanium alloys. JOM 2008, 60, 46-49. [CrossRef] 